\section{Self-efficacy Is a Valuable Predictor of Extension Master Gardeners' Likelihood to Continue Volunteering in the Program}

\author{
Elizabeth A. Gall ${ }^{1}$, B. Rosie Lerner ${ }^{1}$, and Kathryn S. Orvis ${ }^{1,2}$
}

ADDITIONAL INDEX WORDs. consumer horticulture, extension, predictive model, volunteer, volunteer behavior

SUMMARY. In the United States, more than 80 million households participate in some type of gardening activity, including lawn care, vegetable gardening, and flower gardening. This considerable interest in gardening has led to the demand for accurate information about horticultural topics, trends, and research. One credible source for this information is the Extension Master Gardener (MG) Program, of which volunteering is a foundational component. Descriptive characteristics of Purdue Master Gardener (PMG) and PMG interns, characteristics of program participation, and volunteer behaviors were measured through an online survey questionnaire. Demographics, attitudes, self-efficacy, participation in the PMG program, and prior volunteering experience were measured and relationships between predictive variables and total volunteer hours were explored. Overall, the data revealed participants $(\mathrm{N}=673)$ had strong positive attitudes about volunteering. Participants also reported having increased self-efficacy through participation in the MG program, and attitudes and self-efficacy were highly correlated. Based on the results and theoretical framework, a model was developed that can be used to predict volunteering behaviors within MG programs. The predictive model for volunteering behavior revealed that the number of years as an MG and the participant's level of self-efficacy were good predictors of the total number of volunteer hours.

$\mathrm{B}$ oth volunteering and gardening are large components of American society. In $2018,77.4$ million Americans volunteered, resulting in an estimated $\$ 167$ billion economic impact (Corporation for National and Community Service, 2012), and 74\% of all United States households participated in some type of gardening activity (National Garden Research, 2017). Because such a large portion of the American population partaking in both gardening and volunteer activities, it is vital for the public to have accurate information about horticultural topics, trends, and research.

Received for publication 11 Sept. 2019. Accepted for publication 14 Apr. 2020.

Published online 28 May 2020

${ }^{1}$ Department of Horticulture and Landscape Architecture, Purdue University, Ag Mall, West Lafayette, IN 47904

${ }^{2}$ Department of Agricultural Sciences Education and Communication, Purdue University, 915 West State Street, West Lafayette, IN 47907

We thank Krystin R. Bodden, Mark Tucker, Steve McKinley, and John Orick for their contributions and assistance with the development of this manuscript.

K.S.O. is the corresponding author. E-mail: orvis@ purdue.edu.

This is an open access article distributed under the CC BY-NC-ND license (https://creativecommons.org/ licenses/by-nc-nd/4.0/).

https://doi.org/10.21273/HORTTECH04505-20
To this end, the Extension Master Gardener (MG) program has become an established nationwide framework for participants to increase their own horticultural knowledge while simultaneously providing volunteer service opportunities to help further disseminate horticultural information to the public (Boyer et al., 2002; Davenport-Hagen et al., 2018; Dorn et al., 2019). Although specific topics vary nationally, MG participants typically receive educational training in core areas such as plant science, plant pathology, plant nutrition, insect pests, weed identification and management, pesticide safety, and soils (Purdue University, 2018a). Participants who successfully complete the training sessions and pass a knowledge examination are awarded the title of Extension Master Gardener intern, at which point they are encouraged to complete a set amount of volunteer service hours to be awarded the certification of Master Gardener. Volunteering is a required and fundamental component of the MG program. Historically, most MGs' volunteer time was spent answering questions in person at the extension office or during horticultural hotline phone calls (Meyer, 2007). Presently, volunteer opportunities are numerous and include helping with demonstration gardens, community gardens, displays and booths at county and state fairs, youth gardening education, and a multitude of other activities that improve the environment or community (Chalker-Scott and Collman, 2006; Dorn et al., 2018; Meyer, 2007).

Master Gardener participants most often engage in the program due to the desire for horticultural knowledge, desire to contribute to the community, and perceived social aspects of the program (Boyer et al., 2002; Dorn et al., 2018; Schrock et al., 2000; Strong and Harder, 2010, 2011; Wilson and Newman, 2011). Regardless of what brought a participant to the MG program, the main goal of the program is to educate the public about horticultural topics (Bauske et al., 2011; Bobbitt, 1997; Chalker-Scott and Collman, 2006; Meyer, 2007). Prior research has provided a snapshot of typical MGs. Participants are generally older (between ages 51 and 70 years), married, white (non-Hispanic), and female; furthermore, they have advanced degrees and incomes higher than the median in the Unites States (Dorn et al., 2018; Rohs et al., 2002). A large number of volunteers remain active in the program for many years because they perceive many personal benefits of the program, including the personal value of the horticultural knowledge gained through the program, the perception of prestige, and the flexibility in the volunteer service activities conducted and completed (Meyer, 2007; Schrock et al., 2000; Takle et al., 2016). However, retention of participants is a concern within the MG program because many members do not remain active (Meyer, 2004; Stouse and Marr, 1992; Takle et al., 2016).

The social and economic impacts of the $\mathrm{MG}$ are substantial. For example, in 2018 , Indiana reported 2800 active MGs contributing more than 175,000 volunteer hours to their communities (Purdue University, 2018b). This is the equivalent of contributing $\$ 4.3$ million in volunteer services to their communities (Independent Sector, 2019). With such a large interest and investment in the MG program, it is important to examine who the participants are in this program and why they are volunteering, which may help predict future volunteer behaviors.

This study sought to identify potentially predictive variables of volunteering behaviors of participants 
and interns in the Purdue Master Gardener (PMG) program and describe the characteristics and perceptions of participants in the PMG program. Supported by the Theory of Planned Behavior (TPB) as the conceptual framework, potential predictive variables were identified as demographics, attitudes, self-efficacy, participation in the PMG program, and prior volunteering experience. TPB was selected because it attempts to explain and predict behaviors, and it considers the factors of attitudes and self-efficacy in the prediction of behavior and, in this case, volunteer behavior of the PMGs (Ajzen, 1991).

Variables for this study are grounded in prior research of the MG programming or volunteering behaviors. Research has shown demographic variables to be predictors of volunteering behaviors (Tang, 2006; Wilson, 2000). However, volunteering behaviors were not consistently predicted by attitudes about volunteering (Wilson, 2000). Wilson (2000) stated that values (attitudes) fail to predict volunteering, possibly because there are many different contexts of volunteering and because different values (attitudes) influence volunteering in each different context. However, Norman and Rumelhart (1975) posited that when attitudes are combined with other variables, they have a stronger predictive ability than when measured alone. Weber et al. (2004) defined self-efficacy in the volunteering sector as a belief that one can make an impact on the community, and this definition was used in the current study. Self-efficacy has been shown to be a strong predictor of behavior (Bandura, 1986, 1989). When measured in the context of volunteering behaviors, some researchers have found that self-efficacy helps to predict volunteering behaviors (Weber et al., 2004).

There are many ways to characterize prior volunteer experience, such as whether the individual previously volunteered, the type of volunteering activities, participation in servicelearning programs, and the age when an individual volunteered. Past volunteer experience may help to predict volunteering behavior (Janoski et al., 1998; Mutchler et al., 2003). Research supports the idea that adolescents who volunteer may also continue volunteering as adults. If an adolescent has formed positive attitudes about volunteering, then that adolescent is more likely to volunteer later in life (Janoski et al., 1998). Observing a parent or adult role model volunteering or making positive associations with volunteering because of that parent or adult role model may help to predict if adolescents will volunteer as adults (Hamilton and Fenzel, 1988).

A focus on either one or two predictive variables is common throughout most research of the identification of predictive variables for volunteering behaviors. Combining multiple potentially predictive variables, as in the current study, may more effectively predict volunteer behaviors. Attitudes may have stronger predictive abilities when measured in conjunction with multiple predictive variables (Millar and Tesser, 1989). In other words, no one variable can predict volunteering behaviors, but multiple variables have the possibility to effectively predict volunteering behaviors. The purpose of this work was to create a predictive model guided by the TPB and the conceptual model along with key factors of the PMG program to enable the prediction of volunteer behavior.

\section{Materials and methods}

To describe characteristics and perceptions of participants in the PMG program, as well as to identify potentially predictive variables for volunteering behaviors, a web-based questionnaire using an online survey platform (Qualtrics, Provo, UT) was created. This instrument was developed based on previous instruments used for the improvement of the PMG program, and it used items from prior studies (as written or adapted for this questionnaire) (Chapin et al., 2009; Furco et al., 1999; Weber et al., 2004). A pilot test was conducted using the questionnaire for MGs in a county excluded from the final questionnaire to address validity and reliability $(\mathrm{n}=$ 75 ), and adaptations to the final version were made to increase reliability (Cronbach, 1951). Both quantitative and qualitative items were included in the final questionnaire, which totaled 88 items.

Distribution of the questionnaire was performed electronically through PMG county coordinators in counties with PMG programs, which resulted in 500 responses from PMGs and 173 responses from PMG interns (total of 673 responses). Respondents had $\approx 2$ weeks to complete the questionnaire. At the 2-week deadline, a reminder was sent to all coordinators to e-mail participants and allow an extra $2 \mathrm{~d}$ to complete the questionnaire. Because the exact number of potential respondents who viewed the survey is unknown due to the nature of electronic distribution, a response rate could not be calculated. Estimations of distribution based on county MG populations would be speculative; therefore, they were not performed. Respondents who completed the questionnaire could print the last page to receive credit for completion ( $1 \mathrm{~h}$ of volunteer service) from their county $\mathrm{MG}$ coordinator.

The questionnaire focused on predictive variables and included one section about each of the five potentially predictive variables for volunteering behaviors: demographics (10 items), attitude (11 items), self-efficacy (12 items), participation in the PMG program ( 5 items), and prior volunteering behavior ( 8 items). The dependent variable measured was the total volunteer hours per month. Asking respondents to report volunteering behaviors in smaller amounts such as per week or per month, as opposed to per year, may help to aid in recall, as posited by Steinberg et al. (2002). A 7-point scale with scores ranging from "strongly disagree (1 point)" to "strongly agree (6 points)" and "no opinion ( 7 points)" was used for self-efficacy, attitude, and volunteer behavior items.

The statistical analysis included responses from 673 PMGs and interns, and it was completed using statistical software (SPSS version 19.1; IBM Corp., Armonk, NY). Descriptive statistics, Pearson's $r$ correlations, point biserial correlations, and one-way analysis of variance (ANOVA) were used to analyze data. Relationships between items within variables and total volunteer hours per month were measured with Pearson's $r$ correlations for independent variable items measured using an ordinal scale. The assumption of an interval level of measurement was made to calculate Pearson's $r$ using ordinal scale items. A point biserial correlation was calculated when at 
least one of the variables was a nominal dichotomous variable. The interpretation of a positive or negative correlation was not possible within a nominal level of measurement; therefore, only the strength $(r)$ is reported. The point biserial correlation was interpreted according to the same scale as Pearson's $r$ correlation (scale: $0.0-0.09=$ none; $0.1-0.3=$ small; $0.3-0.5=$ medium; and $0.5-$ $1.0=$ strong). The interpretation scale for $r^{2}$ was as follows: $0.01-0.08=$ small; 0.09-0.24 = medium; and $>0.25=$ large (Cohen, 1988). The scale for the interpretation of $r^{2}$ was more conservative than the scale for Cohen's $d$. The interpretation scale for the effect size of an ANOVA relationship $\left(\eta^{2}\right)$ was the same as indicated by the guidelines for Cohen's $r^{2}$ (Cohen, 1988). The effect size was calculated to determine the magnitude of the effect (whether one would expect to see that relationship in the population).

Ordinal logistic regression was used to construct a predictive model of total volunteer hours per month with the following items as independent variables: education, self-efficacy, years as a MG, whether someone had volunteered before participating in the PMG program, prior service-learning experience, whether someone had volunteered as a child or young adult, and whether someone had influential adults in his or her life who emphasized volunteering. Logistic regression does not produce an R-square statistic comparable to that generated by linear regression. However, a pseudo R-square described by Nagelkerke (1991) provides an indication of the relative performance of models in which maximum likelihood rather than explained variance is the chief criterion.

IRB exemption approval was sought and granted for this research (IRB Protocol 1103010677; Apr. 2011).

\section{Results}

Predictive variables. Descriptive statistics were used to evaluate demographic data. More females $(537 ; 79.8 \%)$ than males (134; $19.9 \%)$ responded to the questionnaire. The median age range of respondents was 55 to 64 years (258; $38.3 \%)$. Approximately one-fifth (146;21.7\%) of respondents reported their age as 45 to 54 years and approximately one-quarter of respondents reported their age as 65 to 74 years $(169 ; 25.1 \%)$. The highest level of education achieved by respondents was self-reported, with the greatest frequency earning a bachelor's degree (218;32.4\%), followed by a master's degree $(152 ; 22.6 \%)$, and some college experience $(135 ; 20.1 \%)$. An associate's degree $(77 ; 11.4 \%)$, high school diploma/general education diploma (GED) $(54 ; 8.0 \%)$, doctoral degree $(30 ; 4.5 \%)$, and prefer not to answer/missing data $(7 ; 1.0 \%)$ were the remaining categorical demographic responses. Additional demographics not reported here include occupation, self-reported gross estimated household median income, marital status, number of people who live in the household, county of participation, race, and ethnicity. Several statistically significant relationships among these variables were revealed; however, only those with medium correlation (0.09-0.24 = medium and $>0.25=$ large) or higher are included here and were not included in the predictive model.

PMGs and interns reported attitudes about volunteering for nine items $(\alpha=0.892)$. The highest mean response was for the item "Involvement in programs to improve my community is important" (mean = 5.35 ), followed by "I believe it is important for me to give back to my community by giving of my knowledge" (mean = 5.23) and "I believe it is a citizen's responsibility to participate in community service" ( mean = 5.22).

PMGs and interns reported selfefficacy to make a positive impact and self-efficacy of capacity to volunteer, which were combined into the selfefficacy scale $(\alpha=0.852)$. The highest mean response for self-efficacy items on the 7-point scale was for the item "I am able to gain the skills necessary to volunteer" (mean $=5.33)$, followed by "I have the skills necessary to volunteer" (mean $=5.25)$ and "I have confidence in my ability to help others" $($ mean $=5.21)$.

Regarding participation in the PMG program scale (five items), Cronbach's alpha reliability $(\alpha=$ 0.542 ) deemed this scale as not reliable. Respondents identified as MGs or interns self-reported the number of years as a PMG $(\mathrm{N}=500)$. Therefore, Interns $(\mathrm{N}=173)$ were not grouped into this category. The median number of years participating category ranged from 1 to 5 years (222; $44.4 \%)$. Almost one-third of respondents $(135 ; 27.0 \%)$ indicated participating in the program for 6 to 10 years, followed by 11 to 15 years $(78$; $15.6 \%$ ).

Respondents reported information about prior volunteering experiences before participating in the PMG program (Table 1). Cronbach's alpha reliability regarding the prior volunteering experience scale of eight items ( $\alpha=0.100)$ was not considered to be reliable. However, information is still included here because prior research indicates that these items have particular influence on volunteering experiences (Hamilton and Fenzel, 1988; Janoski et al., 1998; Mutchler et al., 2003; Weber et al., 2004).

RELATIONSHIPS BETWEEN VARIABLES. Relationships between demographic items, attitudes, selfefficacy, and participation and the dependent variable of total volunteering hours per month by PMGs were measured with Pearson's $r$ correlations and one-way ANOVA (Table $2)$. Both attitude items (9 items) and self-efficacy items (10 items) were collapsed into a single scale (adding responses from each individual item and dividing by the total number of items). Theses combined scales were correlated against total volunteering hours per month, and a statistically significant relationship was found among total volunteer hours per month, attitudes, and self-efficacy.

Predictive model. Ordinal logistic regression was used to assess the utility of the theoretical model developed for this study. Variance in the dependent variable, total volunteer hours per month, was regressed against seven independent variables: education, self-efficacy, years as a $\mathrm{MG}$, whether the respondent had volunteered before participation in the PMG program, service-learning, volunteering as a child or young adult, and whether influential adults in the respondent's life emphasized volunteering. Self-efficacy has been shown to predict volunteer behavior (Ajzen, 1991; Bandura, 1986, 1989; Weber et al., 2004) more consistently than attitudes (Janoski et al., 1998). An assumption in the calculation of an ordinal regression is that no two variables will be too highly correlated 
Table 1. Frequency distribution of prior volunteering experiences of Purdue Extension Master Gardeners $(\mathrm{N}=673)$.

\begin{tabular}{lcc}
\hline Prior volunteering experience & $\mathbf{n}$ & $\mathbf{\%}^{\mathbf{z}}$ \\
\hline Volunteering activity $^{\mathrm{y}}$ & & \\
$\quad$ Church or faith-based & 385 & $\mathbf{5 7 . 2}$ \\
$\quad$ Educational or youth-serving & 270 & 40.1 \\
$\quad$ Social or community service & 256 & 38.0 \\
$\quad$ Civic, political, or professional & 244 & 36.3 \\
$\quad$ Sports, hobby, cultural, or arts & 237 & 35.2 \\
Service-learning experience & & \\
$\quad$ Did not have & 452 & 67.2 \\
Volunteered as a child or young adult & & 53.0 \\
$\quad$ Yes & 357 & 47.0 \\
$\quad$ No & 316 & \\
Influential adults emphasized importance of & & 51.0 \\
$\quad$ volunteering & & 49.0 \\
$\quad$ Yes & 343 & \\
$\quad$ No & 330 & \\
\hline
\end{tabular}

${ }^{\mathrm{z}}$ This item contains no missing data.

${ }^{\mathrm{y}}$ Only the top five prior volunteering experiences are shown.

Table 2. Correlation between predictive variables and total volunteer hours per month of Purdue Extension Master Gardeners.

\begin{tabular}{lccc}
\hline Questionnaire item & $r$ & $P^{\mathrm{z}}$ & $r^{2}$ \\
\hline Education & 0.089 & $0.021^{*}$ & 0.008 \\
Attitudes (combined scale) & 0.138 & $0.001^{* * *}$ & 0.019 \\
Self-efficacy (combined scale) & 0.227 & $<0.001^{* * *}$ & 0.052 \\
Intern or Master Gardener & $0.210^{\mathrm{y}}$ & $<0.001^{* * *}$ & 0.044 \\
Years as Master Gardener & 0.180 & $<0.001^{* * *}$ & 0.032 \\
Volunteering activity & & & \\
$\quad$ Church or faith-based & 0.137 & $<0.001^{* * *}$ & 0.19 \\
$\quad$ Educational or youth-serving & $0.54^{\mathrm{y}}$ & 0.160 & - \\
$\quad$ Social or community service & $0.131^{\mathrm{y}}$ & $<0.001^{* * *}$ & 0.017 \\
$\quad$ Civic, political, or professional & $0.141^{\mathrm{y}}$ & $<0.001^{* * *}$ & 0.020 \\
$\quad$ Sports, hobby, cultural, or arts & $0.85^{\mathrm{y}}$ & 0.28 & 0.007 \\
Influential adults emphasized volunteering & $0.119^{\mathrm{y}}$ & $0.002^{* *}$ & 0.014 \\
Service-learning & $0.087^{\mathrm{y}}$ & $0.024^{*}$ & 0.008 \\
Volunteered as a child or young adult & $0.068^{\mathrm{y}}$ & 0.079 & -
\end{tabular}

${ }^{\mathrm{z}}$ Significance level is $0.05 .{ }^{*},{ }^{* *},{ }^{* * *}$ Significant at $P<0.05,0.01$, or 0.001 , respectively.

${ }^{\mathrm{y}} r\left(\mathrm{pb}_{\mathrm{pb}}\right)=$ point biserial correlation.

with each other. The relationship between attitudes and self-efficacy $(r=0.676)$ violated this assumption; therefore, self-efficacy was chosen to be in the model because it has been shown to be a more consistent predictor of volunteer behavior than attitudes. Associated statistics for the ordinal logistic procedure are provided in Table 3 .

Two variables, self-efficacy and years as a $M G$, were statistically significant. The parameter estimates revealed that a l-unit increase in self-efficacy led to a 0.715 increase in the ordered log odds of being in a higher level of total volunteer hours per month. Individuals who express a higher level of self-efficacy are more likely to devote a greater number of hours to volunteering. Statistically significant results were shown for less than 1 year as a MG as the response to the independent variable "years as a MG." Regression results revealed a 0.808 decrease in the log odds of MGs with less than 1 year of participation in the PMG program after earning the certification of "Master Gardener," which indicated a higher level of total volunteer hours per month. Those with less than 1 year of being a MG were less likely to devote a greater number of hours to volunteering per month compared with individuals with more years of participation in the MG program.

The results of the predictive model and the associated parameter estimates for each statistically significant variable can be entered into an equation to highlight the association between the variables and the dependent variable of total volunteer hours per month. The Nagelkerke pseudo Rsquare for the final model was 0.141, indicating a modest performance of independent variables predicting change in levels of the dependent variable. The equation is $(\mathrm{N}=601 ; P=0.05)$ as follows:

Total MG volunteer hours per month $=0.715($ self - efficacy $)+-0.905$

(years as PMG-intern $)+-0.808$

(year as a PMG - less than 1 year)

\section{Discussion}

Consistent with prior MG research, results of the self-efficacy, attitude, and volunteering items in this study indicated that the MG program is making positive impacts on both PMGs and their communities through effective training, appropriate logistics, and dissemination of horticultural research by the land grant university. Most PMG interns and PMGs indicated commitment to the community through strong positive attitudes about volunteering in the MG program, and they had previously volunteered for a number of other organizations to make positive impacts on the community. Participation in the $M G$ program also increased their self-efficacy. This evidence may help to validate the time, energy, and resources invested by the National Institute of Food and Agriculture and land grant universities to implement and maintain the $M G$ program.

Identification of potentially predictive variables for volunteering behaviors led to the development of the predictive model with the variables of self-efficacy and years as a MG (less than 1 year as a MG). These results showed significant effects in the model for this study. Respondents who have been MGs for less than 1 year are less likely to devote more time to volunteering than those who have been in the MG program for longer periods. Therefore, retention of experienced volunteers is important to increasing the total hours volunteered through the MG program. The model indicated that helping programs foster and increase self-efficacy 
Table 3. Predictive model of total volunteer hours per month regressed against seven independent variables of Purdue Extension Master Gardeners by ordinal logistic regression $(\mathrm{N}=601)$.

\begin{tabular}{|c|c|c|c|c|}
\hline Variable & Parameter estimate & SE & Wald statistic & $P^{\mathrm{z}}$ \\
\hline Self-efficacy & 0.715 & 0.147 & 23.565 & $<0.001^{* * *}$ \\
\hline \multicolumn{5}{|l|}{ Education } \\
\hline High school diploma/GED & -0.742 & 0.435 & 2.911 & 0.088 \\
\hline Some college experience & -0.467 & 0.384 & 1.482 & 0.223 \\
\hline Associate's degree & -0.590 & 0.411 & 2.064 & 0.151 \\
\hline Bachelor's degree & -0.391 & 0.364 & 1.152 & 0.283 \\
\hline Master's degree & -0.506 & 0.374 & 1.829 & 0.176 \\
\hline Doctorate degree & $0^{y}$ & - & - & - \\
\hline \multicolumn{5}{|l|}{ Years as a Master Gardener } \\
\hline Intern & -0.950 & 0.258 & 13.529 & $<0.001 * * *$ \\
\hline Less than 1 year & -0.808 & 0.353 & 5.250 & $0.022 *$ \\
\hline $1-5$ years & 0.097 & 0.236 & 0.167 & 0.682 \\
\hline $6-10$ years & -0.178 & 0.259 & 0.475 & 0.491 \\
\hline 11 or more years & $0^{\mathrm{y}}$ & - & - & - \\
\hline Before volunteering: no & -0.420 & 0.290 & 2.091 & 0.148 \\
\hline Before volunteering: yes & $0^{y}$ & - & - & - \\
\hline Service-learning: yes & 0.256 & 0.166 & 2.376 & 0.123 \\
\hline Service-learning: no & $0^{\mathrm{y}}$ & - & - & - \\
\hline Volunteered as child or young adult: yes & 0.111 & 0.168 & 0.438 & 0.508 \\
\hline Volunteered as child or young adult: no & $0^{y}$ & - & - & - \\
\hline Influential adults emphasized volunteering: yes & 0.154 & 0.173 & 0.790 & 0.374 \\
\hline Influential adults emphasized volunteering: no & $0^{y}$ & - & - & - \\
\hline$-2 \log$ likelihood & 1443.74 & & & \\
\hline$\chi^{2}$ & 1643.66 & & & \\
\hline $\mathrm{df}$ & 14 & & & \\
\hline Nagelkerke $R^{2}$ & 0.141 & & & \\
\hline
\end{tabular}

${ }^{\mathrm{z}}$ Significance level is $0.05 .{ }^{*},{ }^{*},{ }^{*} * *$ Significant at $P<0.05,0.01$, or 0.001 , respectively.

${ }^{\mathrm{y}}$ This parameter is set to zero because it is redundant.

will keep PMGs active in the program. The use of mentors to encourage new interns may lead to retention and increased self-efficacy of participants. This finding is consistent with that of Jacobs (2018), who indicated that volunteer satisfaction and organizational commitment were related to intentions to leave the MG program.

Limitations to the methodology used in this study include low reliability of the prior volunteering experience and of the participation in the PMG program scales; therefore, caution is suggested when interpreting the results of the study. The questionnaire and predictive model developed for this study have limited generalizability to other populations due to their specificity to the PMG program. However, many of the items may have relevance or application to other volunteering contexts and within the MG program regionally and nationally.

Interesting questions for additional study may include how to retain MG interns and new MG volunteers. Within the MG program, the influence of additional individuals could be studied to determine who may be agents for fostering or increasing self-efficacy in PMGs and interns because self-efficacy has been found, in this study, to increase the total amount of volunteer hours of participants.

In conclusion, through the identification of potentially predictive variables for volunteer behavior and building a predictive model based on those potentially predictive variables guided by the TPB, this study contributes to the knowledge of $\mathrm{MG}$ volunteer behaviors and the national MG program. The predictive model may provide a framework for measuring total volunteer hours per month within the PMG program. An individual's self-efficacy and years as a $\mathrm{MG}$ can be used to potentially predict his or her total volunteer hours per month. This has important implications for use within MG programs because administrators and coordinators could observe or measure selfefficacy and how long an individual has been participating in the program to potentially gauge how much participants will volunteer.

\section{Literature cited}

Ajzen, I. 1991. The theory of planned behavior. Organ. Behav. Hum. Decis. Process. 50(2):179-211.

Bandura, A. 1986. Social foundations of thought and action: A social cognitive theory. Prentice Hall, Englewood Cliffs, NJ.

Bandura, A. 1989. Human agency in social cognitive theory. Amer. Psychol. 44(9):1175-1184.

Bauske, E.M., L. Kelly, K. Smith, L. Bradley, T. Davis, and P. Bennett. 2011. Increasing effectiveness of Cooperative Extension's Master Gardener volunteers. HortTechnology 21:150-154.

Boyer, R., T.M. Waliczek, and J.M. Zajicek. 2002. The Master Gardener program: Do benefits of the program go beyond improving the horticultural knowledge of the participants? HortTechnology 12:432436.

Bobbitt, V. 1997. The Washington State University Master Gardener Program: 
Cultivating plants, people, and communities for 25 years. HortTechnology 7:345-347.

Chalker-Scott, L. and S.J. Collman. 2006. Washington State's Master Gardener Program: 30 years of leadership in university-sponsored, volunteer-coordinated, sustainable community horticulture. J. Clean. Prod. 14(9-11):988-993.

Chapin, J., J. Levings, and P.L. Nippolt. 2009. North Central Region 4-H volunteers documenting their contributions and volunteer development: Sept. 2009. 30 Aug. 2019. <http://citeseerx.ist.psu. edu/viewdoc/download?doi=10.1.1. 296.1760\&rep $=$ repl \& type $=p d f>$.

Cohen, J. 1988. Statistical power analysis for the behavioral sciences. Erlbaum, Hillsdale, NJ.

Corporation for National and Community Service. 2012. Volunteering in the U.S. hits record high; worth $\$ 167$ billion. 30 Aug. 2019. Lhttps://www. nationalservice.gov/newsroom/pressreleases $/ 2018$ /volunteering-us-hitsrecord-high-worth-167-billion>.

Cronbach, L.J. 1951. Coefficient alpha and the internal structure of tests. Psychometrika 16(3):297-334.

Davenport-Hagen, L., J.E. Weisenhorn, and M.H. Meyer. 2018. Applied research engages Extension Master Gardener volunteers. J. Ext. 56(4):4IAW5. 27 Apr. 2020. <https://joe.org/joe/2018august/ iw5.php>.

Dorn, S.T., M.G. Newberry, E.M. Bauske, and S.V. Pennisi. 2018. Extension Master Gardener volunteers of the 21st century: Educated, prosperous, and committed. HortTechnology 28:218229.

Dorn, S., M.G. Newberry, E.M. Bauske, and S.V. Pennisi. 2019. Are we on the same page? Exploring national, state, and local educational-response themes for Extension Master Gardener coordinators and volunteers. HortScience 54:568575 .

Furco, A., M. Ammon, H. Yamada, and D. Diaz-Gallego. 1999. Service learning survey. Univ. California, Berkeley.

Hamilton, S.F. and L.M. Fenzel. 1988. The impact of volunteer experience on adolescent social development: Evidence of program effects. J. Adolesc. Res. 3(1):65-80.

Independent Sector. 2019. 2018 Annual Report. 27 Apr. 2020. <https:// independentsector.org/resource/2018annual-report $>$.

Jacobs, A.P. 2018. Exploring the relationship between volunteer motives, satisfaction, commitment, and intention to leave the Mississippi Master Gardener Program. PhD Diss., Mississippi State Univ., Mississippi State.

Janoski, T., M. Musick, and J. Wilson. 1998. Being volunteered? The impact of social participation and pro-social attitudes on volunteering. Sociol. Forum 13(3):495-519.

Meyer, M.H. 2004. Why Master Gardeners stop volunteering: Lack of time. Hort Technology 14:437-438.

Meyer, M. 2007. The Master Gardener program 1972-2005. Hort. Rev. 33:393420 .

Millar, M.G. and A. Tesser. 1989. The effects of affective-cognitive consistency and thought on the attitude-behavior relation. J. Expt. Soc. Psychol. 25(2):189202.

Mutchler, J.E., J.A. Burr, and F.G. Caro. 2003. From paid worker to volunteer: Leaving the paid work-force and volunteering in later life. Soc. Forces 81(4):1267-1293.

Nagelkerke, N.J. 1991. A note on the general definition of the coefficient of determination. Biometrika Trust 78(3):691692.

National Garden Research. 2017. Slow and steady wins the race: Gardening grows thanks to millennials. 30 Aug. 2019. <https://gardenresearch.com/ blog/gardening-grows-thanks-tomillennials $/>$.

Norman, D.A. and D.E. Rumelhart. 1975. Explorations in cognition. LNR Res. Group Publ., San Francisco, CA.

Purdue University. 2018a. Become a Purdue Master Gardener. Purdue Ext. Publ. HO-184. 20 Aug. 2018. <https:// www.purdue.edu/hla/sites/mastergardener/how-do-i-become-a-purduemaster-gardener $/>$.

Purdue University. 2018b. Purdue Extension Master Gardener Program annual report. 20 Aug. 2018. <https://www. purdue.edu/hla/sites/master-gardener/ wp-content/uploads/sites/9/2019/ $10 / \mathrm{MG}$-annual-report-web-2018revised 1023.pdf>.

Rohs, F.R., J.H. Stribling, and R.R. Westerfield. 2002. What personally attracts volunteers to the Master Gardener Program? J. Ext. 40(4):1-9. 27 Apr. 2020. <https://www.joe.org/joe/ 2002august/rb5.php>.

Schrock, D.S., M.H. Meyer, P. Ascher, and M. Snyder. 2000. Reasons for becoming involved as a Master Gardener. HortTechnology 10:626-630.

Steinberg, K.S., P.M. Rooney, and W. Chin. 2002. Measurement of volunteering: A methodological study using Indiana as a test case. Nonprofit Volunt. Sector Q. 31(4):484-501.

Stouse, L. and C. Marr. 1992. Retaining Master Gardener volunteers. HortTechnology 2:244-245.

Strong, R. and A. Harder. 2010. Master Gardeners' teaching efficacy and demographic characteristics as volunteer educators for Cooperative Extension. J. South. Agr. Educ. Res. 60(1):13-24.

Strong, R. and A. Harder. 2011. Interactions among instructional efficacy, motivational orientations, and adult characteristics on Master Gardener tenure. J. Ag. Ed. 52(4):65-75.

Takle, B., C. Haynes, and D. Schrock. 2016. Motivation and retention of Iowa Master Gardeners. HortTechnology 26:522529.

Tang, F. 2006. What resources are needed for volunteerism? A life course perspective. J. Appl. Gerontol. 25:375-390.

Weber, P., J.E. Weber, B.J. Sleeper, and K.C. Schneider. 2004. Self-efficacy toward service, civic participation, and the business student: Scale development and validation. J. Bus. Ethics 49(4):359-369.

Wilson, J. 2000. Volunteering. Annual Review of Sociology 26(1):215-240.

Wilson, J.C. and M.E. Newman. 2011. Reasons for volunteering as a Mississippi Master Gardener. J. Ext. 49(5):5RIB1. 27 Apr. 2020. <https://www.joe.org/joe/ 201 loctober/pdf/JOE_v49_5rbl.pdf>. 